\title{
Perfil clínico e sociodemográfico de indivíduos com disfunção temporomandibular atendidos no projeto Alívio
}

\author{
Anne Karoliny Amparo Cardoso ${ }^{(D)}$, Annelise Corona Delpuppo Da Silva ${ }^{(D)}$, Juliana Zuculoto Da Fonseca ${ }^{(D)}$, \\ Dhandara Araújo De Sousa ${ }^{(D)}$, Cintia Helena Santuzzi ${ }^{D}$, Fernanda Mayrink Gonçalves Liberato ${ }^{(D)}$
}

Universidade Federal do Espírito Santo, Vitoria, Espirito Santo, Brasil.

\section{Introdução}

A Disfunção Temporomandibular (DTM) compõe um coletivo de afecções cujos sintomas incluem dores na face e cefaleia.

\section{Objetivos}

Definir o perfil clínico e sociodemográfico dos pacientes com DTM atendidos no projeto Alívio da UFES.

\section{Material e Métodos}

Trata-se de um estudo descritivo. Colheu-se dos prontuários: idade, sexo, estado civil, número de filhos, tempo e intensidade da dor (EVN), consultas prévias ao projeto, diagnóstico clínico pelo DC/TMD, dados de questionários de incapacidade cervical (NDI) e limitação de função mandibular (MFIQ).

\section{Resultados}

Entre novembro/2020 e agosto/2021 foram atendidos 19 pacientes. $83,3 \%$ eram do sexo feminino, com média de idade de $38.06( \pm 14.3)$ anos, $50 \%$ solteiros, $44,4 \%$ casados e $5,6 \%$ divorciados e média de 0,61 filhos. Consultaram-se anteriormente ao projeto em média com 2 profissionais, sendo eles $83,3 \%$ dentistas, $33,3 \%$ médicos e $27,8 \%$ fisioterapeutas. Todos apresentavam dor crônica (>3 meses) e a dor média foi de $4,32( \pm 2,6)$. O diagnóstico de DTM pelo DC/TMD revelou que $88,9 \%$ tinham mialgia e $77,8 \%$ artralgia; $88,9 \%$ mialgia e artralgia. $38,9 \%$ dos pacientes tiveram diagnóstico de cefaleia atribuída à DTM, 61,1\% deslocamento de disco articular, 44.4\% doença articular degenerativa e $11,1 \%$ subluxação. O NDI evidenciou os respectivos percentuais de incapacidade cervical: $27,8 \%$ nenhuma, 33,3\% leve, $16,7 \%$ moderada e $16,7 \%$ severa. O MFIQ revelou o mesmo percentual de incapacidade mandibular (38,9\%) para escores baixo e moderado e $22,2 \%$ escore severo.A literatura evidencia a prevalência do gênero feminino com DTM, maior frequência de DTM do tipo mista ou mialgia, sendo a tensão cervical um dos fatores desencadeantes/perpetuantes de dor e cefaleia, resultando em algum grau de incapacidade, tanto mandibular quanto nas atividades de vida diária.

\section{Conclusão}

Apesar da pequena amostra, este estudo revelou o perfil dos pacientes com DTM, permitindo assim criar estratégias de manejo em consonância com esta população.

Palavras-chave: Disfunção temporomandibular, Perfil clínico, Perfil sociodemográfico 